\title{
Bueller...Bueller?: Predictors of Behavioral Engagement, as Measured by Student Attendance, IN A BLENDED MBA ENVIRONMENT
}

\author{
Matthew D. Marmet, Michael McCarthy, \\ Stephanie R. Nesbitt, and Tracy M. Balduzzi
}

Matthew D. Marmet (mdmarmet@utica.edu) is an Assistant Professor of Management in the School of Business and Justice Studies at Utica College, 1600 Burrstone Road, Utica, NY 13502. Michael McCarthy is an Assistant Professor of Data Science at Utica College. Stephanie R. Nesbitt is the Associate Dean of Business and Economics, and Director of MBA Programs at Utica College. Tracy M. Balduzzi is the Executive Coordinator of Graduate Programs at SUNY Upstate Medical University, 766 Irving Avenue, Syracuse, NY 13210. Correspondence concerning this paper should be addressed to Matthew D. Marmet.

\begin{abstract}
This study examined the predictors of student behavioral engagement, as measured by in-class attendance in a blended MBA program at a small, private college in the northeastern United States. In-class attendance was taken at the beginning of each class and students were considered "in attendance" if they were
\end{abstract}


in the physical classroom space, or joined the session virtually via WebEx. Initial considerations of central tendency and correlation are reported. Subsequently, multiple regression analysis was conducted to assess the impact of gender, undergraduate GPA, and years since undergraduate completion on behavioral engagement. Results indicated that all three predictors possessed a significant, positive relationship with the criterion. Of the predictors, undergraduate GPA yielded the strongest relationship with behavioral engagement, while controlling for the other variables. Implications of the findings and potential avenues of future research are discussed, along with limitations and other considerations of the study's methods, procedures and ultimate findings.

Keywords: student demographics, student engagement

Data Availability: Data in this study are not available from public sources

DOI: https://dx.doi.org/10.15239/j.brcadvje.2020.04.01.ja01

\section{LITERATURE REVIEW}

\section{Student Engagement}

Although prior researchers have defined student engagement in several different ways (Trowler, 2010), the current research effort employs the following definition from Kuh (2009): "The time and effort students devote to activities that are empirically linked to desired outcomes of college and what institutions do to induce students to participate in these activities" (p. 683). This definition speaks to both sides of the equation, with efforts on the part of the students and the institution being necessary to bring engagement to fruition.

In addition to this umbrella definition, prior researchers divided student engagement into three separate dimensions. Fredricks, Blumenfeld, and Paris (2004) identify these dimensions as behavioral, emotional, and cognitive engagement. The focus of this study will be on the behavioral 
dimension of engagement, with a discussion of the other two being beyond the scope of its exploration. This individual construct (for the purposes of this study) is defined as positive conduct and student conformity to school norms, which can range from attending class to simply being polite once a student is within the classroom environment (Archambault, Jauosz, Morizot, \& Pagini, 2009).

The importance of such engagement has been illustrated in previous research. Graham, Tripp, Seawright, and Joeckel (2007) indicate that "a diverse body of educational research has shown academic achievement is positively influenced by the amount of active participation in the learning process" (pp. 233-234). Similarly, Kuh (2009) states that students who devote more time and energy gained more from their studies and other aspects of the college experience than those who did not.

\section{Measuring Behavioral Engagement}

Given its demonstrated importance to academic success, being able to measure student behavioral engagement becomes a task of paramount importance. Prior researchers have voiced concern over such measurement, stating that "few researchers have attempted to derive a valid and reliable measure of college student engagement in particular courses" (Handelsman, Briggs, Sullivan, \& Towler, 2005, p. 184). The current project employed a very objective measure of behavioral engagement. As indicated by Archambault and colleagues (2009), this form of engagement can be characterized by activities like attending one's classes. This is what Fredricks, Blumenfeld, and Paris (2004) refer to as a "conduct measure" (p. 65) of engagement. This measure of engagement can include positive behaviors like attending class, but takes negative aspects into account as well, which speaks to the idea of disengagement. Disengagement can manifest itself in the form of frequent absences and tardiness (Fredricks, Blumenfeld, \& Paris, 2004). In addition, the authors also point to commitment being essential to an understanding of engagement. Regarding attendance, those who attend class at higher levels should be considered more committed, or more engaged. 


\section{Engagement as a Criterion}

An interesting point about the research described above is that student engagement is often treated as a predictor variable, particularly for academic success. Behavioral engagement though, seems to be rarely utilized as a criterion variable of interest, especially at the graduate school level. With its known importance, it would seem beneficial to be able to reasonably predict the type of student who will or will not be engaged in their academic courses (more on this in the implications outlined below).

Gender is a demographic variable that has been linked to this form of engagement in the past. In their 2008 study, Eaton, Brener, and Kann found that the majority of absentees were female. What the research seems to lack is how certain demographic variables like gender, and others more specific to graduate level students, could impact student behavioral engagement in this population. This research team argues that this presents a significant gap in the body of research around the topic, and a viable avenue for fruitful investigation.

The exploratory question this research effort seeks to investigate is:

How do gender, undergraduate GPA, and years since undergraduate completion impact student behavioral engagement, as measured by in-class attendance?

What follows in the sections below is a thorough explanation of the data and data analysis techniques employed to help gain a better understanding of the relationships between gender, undergraduate GPA, years since undergraduate completion, and student behavioral engagement. Included in this explanation are results of exploratory descriptive analyses, and the results of multiple regression analysis with all three predictors included in the predictive model. 


\section{MeTHODOLOGY}

\section{Participants}

Data for this study included 1,220 records across numerous classes for 185 students enrolled in a blended MBA program at a small, private academic institution in the northeastern United States. These participants ranged in age from 21 to 57 years, with a mean age of 31. Further information on participant demographics can be found in the Exploratory Data Analysis - Descriptive Statistics section below.

\section{Data Collection}

Attendance data were collected by the primary investigator (PI). As the Education Experience Coordinator for the blended MBA program at the college, part of the PI's role is to sit in on every blended MBA class to ensure there is a real-time connection between the students in the virtual space, and the other students and faculty member(s) who are physically in the classroom. At the start of class, the PI logged the student attendance for each faculty member. The data were collected not only for the professors teaching the courses, but also for the standard administrative purposes of the program itself. The demographic variables of interest, including gender, undergraduate GPA, and years since undergraduate completion were obtained from the college's student records by a research assistant.

Within the dataset itself, attendance was logged by using lettered indicators for the form of attendance the student chose. A "P" was used to indicate a student was physically in the classroom. A "V" was marked next to a student's name if they joined the class virtually via the WebEx platform. If a student did not join the live class in either of those ways, but watched the recording of the class through a link in the Learning Management System (LMS), a "W" went next to their name. An "A" was used to indicate complete absence.

These attendance data were collected during each individual class period over the course of a two year timeframe spanning 2016 and 2017. 
These classes typically ran from 6:00pm to 7:25pm, and then again from $7: 30 \mathrm{pm}$ to $8: 55 \mathrm{pm}$. Unlike a typical undergraduate schedule, the blended MBA classes meet year round, so data were collected for the fall, spring, and summer semesters. The demographic variables were compiled during the spring of 2018 .

\section{RESULts}

\section{Exploratory Data Analysis - Descriptive Statistics}

The first independent variable of interest was gender. In this dataset, gender was a dichotomous variable labeled $1=$ Female and $0=$ Male. The descriptive statistics for gender can be found in Table 1 . Since the mean for gender is . 53 , this means that $53 \%$ of the sample was coded as a " 1. ." In other words, the study sample was made up of $53 \%$ females and $47 \%$ males.

\section{Preview Complete}

This concludes the free, limited preview of this paper. Please buy full access.

\section{Citation Information}

Marmet, Matthew, D., Michael McCarthy, Stephanie R. Nesbitt, and Tracy M. Balduzzi. "Bueller...Bueller?: Predictors of Behavioral Engagement, as Measured by Student Attendance, in a Blended MBA Environment." BRC Journal of Advances in Education 4, no. 1 (2020): 1-15. https:// dx.doi.org/10.15239/j.brcadvje.2020.04.01

\section{Web APPe ndix}

A web appendix for this case is available at: https://dx.doi.org/10.15239/ j.brcadvje.2020.04.01.wa01 